\title{
Impact of Amorphous Precursors on Elemental and Isotopic Signatures of Carbonate Minerals
}

\author{
Bettina Purgstaller ${ }^{1 *}$, Vasileios Mavromatis ${ }^{1}$, \\ KATJA E. GOETSCHL ${ }^{1}$ AND MARTIN DiETZEL ${ }^{1}$
}

${ }^{1}$ Graz University of Technology, Institute of Applied

Geosciences, Rechbauerstraße 12, 8010 Graz, Austria,

*bettina.purgstaller@tugraz.at

The interpretation of elemental and isotopic signatures of carbonate minerals is based on the assumption that they record the chemical and isotopic signals of the aqueous environments at the time of their formation. However, in natural systems carbonate minerals form either by classical nucleation from solution or via the transformation of an amorphous carbonate precursor. The question of how (isotope)chemical signatures are affected during amorphous precursor formation and subsequent transformation is of key relevance for the application of above proxies and requires a detailed understanding about (trans)formation mechanisms. The present work aims at (i) revealing reaction mechanisms controlling distinct carbonate mineral formation via amorphous calcium magnesium carbonate (ACMC) and (ii) evaluating the fate of the primary chemical and isotopic composition of the amorphous precursor.

Formation and transformation of ACMC was studied experimentally at $\mathrm{pH} / \mathrm{T}$-stat conditions using in-situ Raman monitoring and time-resolved sampling/analyses of precipitates and solutions. The obtained results suggest a highly dynamic ion exchange behaviour between the nanoporous ACMC solid phase and the experimental solution. This ion exchange is changing the prevailing solution chemistry $(\mathrm{Mg} / \mathrm{Ca}$ ratio, $\mathrm{pH}$ etc.) which significantly affects ACMC transformation path to yield distinct crystalline hydrous and anhydrous Ca-Mg-carbonates. Essentially, our findings indicate that the fractionation of oxygen and magnesium isotopes between ACMC and solution is different to that expected at isotopic equilibrium for $\mathrm{Mg}$-calcite. The impact of amorphous precursors on elemental and isotopic signatures of carbonate minerals is discussed in the light of (i) various transformation scenarios, like open to closed conditions during transformation, and (ii) implications for the use of elemental and isotope data of carbonate minerals to reconstruct their environmental formation conditions. 